\title{
The effect of visual masking on the critical duration of form
}

\author{
NIGEL R. LONG
}

University of Queensland, St. Lucia, Brisbane, Queensland 4067, Australia

The Ss were briefly shown pairs of letters under various conditions of simultaneous masking. For the simultaneous masking conditions, a single homogeneous flash of light (MS), $1 \mathrm{msec}$ in duration, followed the onset of the letters (TS) at varying onset asy nchronies. The recognition of the TS letters was found to be an increasing function of the MS onset delay. Current theories of form perception and visual masking were examined in the light of this finding.

Recently it has been suggested that the critical duration for form perception is very much greater than would be predicted if form perception were operating with a time-intensity reciprocity (Kahneman \& Norman, 1964; Kahneman, 1966). It appears that for brightness perception the simple multiplicative laws (e.g., Blochs \& Riccos' law) are determined solely by the total amount of energy which reaches the retina irrespective of how the energy is distributed within the critical duration (Blackwell, 1963; Lichtenstein \& Boucher, 1960). Form perception, on the other hand, does not seem to be determined solely by the total amount of energy which reaches the retina, but it is more important that the retina receives sustained stimulation over a critical period (Dainoff \& Haber, 1967; Schurman, Eriksen, \& Rohrbaugh, 1968).

Schurman, Eriksen, \& Rohrbaugh (1968) failed to find a critical duration over which time-intensity reciprocity operates when the form energy was presented in 10 pulses separated by intervals varying from 2 to $48 \mathrm{msec}$. This study confirms that the essential criterion to be met for form perception is that the stimulation must be sustained regardless of whether or not other parameters of the TS are varying. During this critical period of sustained stimulation, the TS icon is undergoing a period of consolidation; hence, it is highly susceptible to visual masking. There is, however, growing evidence which suggests that the consolidating icon is more susceptible to masking at some stages of consolidating than at others (Battersby, Oesterreich, \& Sturr, 1964).

A procedure involving a simultaneous masking paradigm was developed, which enabled the TS and MS to be presented simultaneously without altering the sustained duration of the TS. If the TS duration is very much greater than the MS duration, then the onset and the offset of the MS could occur within the duration of the TS. Provided that the duration and configuration of the MS remained constant, specific effects produced by the MS could possibly be related to the amount of processing the TS has undergone.

In the present experiment several simultaneous masking paradigms are examined in an attempt to test the hypothesis that various stages of consolidation of the TS may be more susceptible to visual masking than others.

\section{SUBJECTS}

One female and seven male volunteers were used. All Ss were experienced tachistoscopic viewers, as they had all taken part in other tachistoscopic experiments. All had normal or corrected-to-normal visual acuity.

\section{APPARATUS}

The apparatus consisted of a three-field tachistoscope. The three fields of the instrument were illuminated by white-coated cold cathode lamps, driven by an automatic electronic programmer. The adaptation field was dark and contained, at its center, four small very dim white dots which lay at the corners of an imaginary rectangle subtending an angle of $58 \mathrm{~min}$ vertically and $33 \mathrm{~min}$ horizontally. The $\mathrm{S}$ was instructed to fixate between the upper and lower pairs of dots as the target letters always appeared between them. Viewing was binocular. In all cases the $S$ initiated the masking sequences by pressing a remote control microswitch.

\section{MATERIALS}

Target Stimuli

The target stimuli consisted of a pair of capital letters (Letraset 287) mounted on a $5 \times 7$ in. off-white board.

Each letter was located 1/4 in. horizontally to the left and to the right of the center of the card. The letters were $6 / 32 \mathrm{in.} \mathrm{high} \mathrm{and}$ subtended visual angles of $13 \mathrm{~min}$ vertically and a maximum of $15 \mathrm{~min}$ horizontally. Viewing of the two target letters was thus foveal.

The stimulus pairs were constructed by drawing from the alphabet pairs of letters by means of a table of random numbers. All letters of the alphabet appeared approximately an equal number of times in either of the two positions.

Three restrictions were placed on the combinations of letters used for the construction of the stimulus cards: (1) No common words or common abbreviations were permitted; (2) no two letters in any pair were identical; and (3) no pair of letters was a reversal of another.

Under these restrictions 230 stimulus cards were manufactured and assigned randomly to 23 sets of 10 cards each. Of these stimulus sets 2 were practice sets, 1 was a threshold set, and 20 were experimental sets.

Order of the presentations of the experimental sets was randomized and balanced over Ss and conditions.

The luminance of the TS was always $1.00 \mathrm{fL}$.

\section{Masking Stimulus}

The masking stimulus consisted of a $5 \times 7$ in. piece of off-white cardboard, of the same manufacture as that used for the stimulus cards. The luminance of the masking stimulus was always $2.50 \mathrm{fL}$. The visual angles subtended by the MS and TS fields were $6.5 \mathrm{deg}$ vertically and $4.3 \mathrm{deg}$ horizontally. The MS duration was always $1 \mathrm{msec}$. PROCEDURE

The $\mathrm{S}$ was given $1 \mathrm{~h}$ of practice in reporting the TS under various simultaneous masking paradigms. These included masking conditions which were similar to those to be encountered later in the experimental conditions. Near the end of the preliminary practice session each S's threshold for a pair of random letters was calculated by an ascending series of the method of limits. This threshold value was subsequently used as the TS duration for the masking paradigms and represents the level at which an $S$ correctly identified two letters $75 \%-80 \%$ of the time without the presence of a mask. The mean TS duration was $4.55 \mathrm{msec}$, while the range was from 3.00 to $6.50 \mathrm{msec}$.

On experimental days the $S$ s were adapted to a low level of illumination for several minutes. They then adjusted their heads to the rubber eyepiece of the tachistoscope until they could see the four white dots clearly with both eyes. The duration of the TS was fixed at the S's threshold for two random letters as determined during the preliminary practice session. The practice TSs were then presented for $10 \mathrm{~min}$. This period served as a warmup and also ascertained whether the $\mathrm{Ss}$ could detect the letters $75 \%-80 \%$ of the time. At the conclusion of warm-up trials the experimental session commenced. 


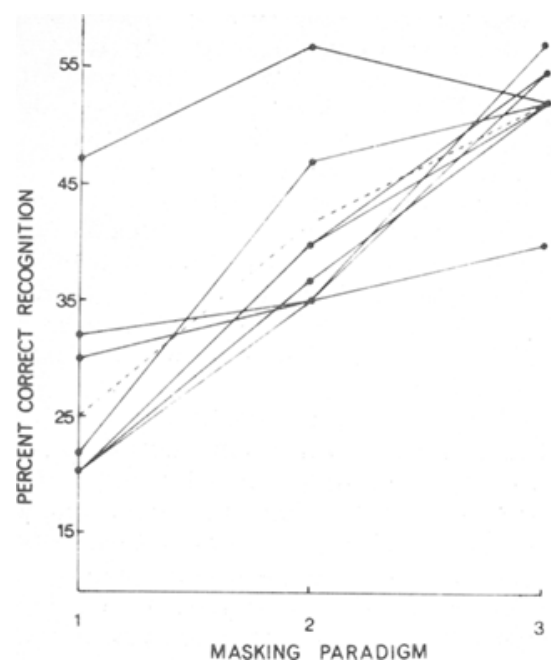

Fig. 1. Percent correct recognition of the TS as a function of masking paradigm. See text for description of masking paradigm. (...) stands for a veraged data.

Three simultaneous masking paradigms were examined as follows: (1) The onset of the TS and the onset of the MS was zero. (2) The MS was presented at the center of the TS duration. (3) The MS was presented before the termination of the TS, so that the offset of the TS and the offset of the MS was zero or very close to it (never greater than $0.6 \mathrm{msec}$ ).

In general terms, during the presentation of the TS, the mask could appear in one of three positions: at the onset, near the midpoint, or near the offset of the threshold duration of the TS.

\section{Miscellaneous Items}

The Ss determined their own rate of presentation of the TS by triggering the display only when they were ready. In all experiments the Ss reported the stimuli verbally. Under all conditions of masking, the Ss were instructed to guess if any of the letters were unclear. This forced-response procedure ensured that unwilling $\mathrm{Ss}$ always responded. Guessing apparently does not affect correct responding but only alters error frequencies (Keppel \& Mallory, 1969). Because of this instruction to guess, reversal of letters was scored as correct. Each letter correctly identified was scorcd 1-the maximum score per experimental set being 20 . The Ss were aware of the restrictions placed upon the construction of the cards and were reminded of them if they were breached.

\section{RESULTS}

Recognition scores which fulfilled the requirements of the three simultaneous masking conditions were compared in an analysis of variance. The effect of delaying the presentation of the mask was significant $[F(2,14)=223.16, \quad p<.01]$ and is shown in Fig. 1. This figure shows a reduction in masking (i.e., an increase in percent correct recognition) across masking paradigms (i.e., delay of MS onset). Only one $S$, the uppermost on the figure, shows an increase in the severity of masking between Masking Paradigms 2 and 3 . The average data also show a reduction in masking with an increase in the delay of MS onset. For all masking paradigms, a 1 -msec MS has a severe masking effect. Figure 1 shows that the criteria for correct identification of the TS in absence of a mask is never reached.

\section{DISCUSSION}

The results of this experiment support the contentions of Schurman, Eriksen, \& Rohrbaugh (1968) and Kahneman (1966); that is, for accurate form perception, the retina must receive sustained stimulation from the TS over a critical duration. In the present study the occurrence of a MS during the presentation of the TS should impair form perception, as a mask is able to alter the sustained presentation of the TS.

The finding that a MS has a severe masking effect when presented at the onset of a TS could account for the absence of a time-intensity reciprocity for form perception. Any event which partitions or interferes with the important initial duration of the TS will effectively prevent accurate form perception. Events which interfere with later durations of the TS prevent form perception to lesser extents.

The method by which the TS prevents the perception of the TS is unclear, but it appears that the MS does not degrade the stimulus input (Robinson, 1968; Liss, 1968). The MS could possibly affect the identification of the TS by making the information contained in the TS unavilablo lo" a few milliseconds. Thus effective "readout" from short-term memory is prevented.

Various attempts have been made to isolate the level of visual processing at which the MS interrupts the identification of the TS (Liss, 1968 Sperling, 1967). Liss (1968) has suggested that the mask prevents a central system from analyzing the stimulus, while Sperling (1967) has suggested that the stimulus is converted into nonverbal memory. Whatever the explanation of visual masking, it seems that the point of disruption must occur relatively high in the temporal processing sequence.

REFERENCES

BATTERSBY, W. S., OESTERREICH, R. E., \& STURR, J. F. Neural limitation of visual excitability. VII Non-homonymous retrochiasmal interaction. American Journal of Physiology, 1964, 206, 1181-1188

BLACKWELL, H $R$. Neural theories of simple visual discriminations. Journal of the Optical Society of America, 1963,53, 129-160.

DAINOFF, M., \& HABER, R. N. How much do repeated presentations give to the recognition processes? Perception \& Psychophysics, 1967, 2, 131-136.

KAHNEMAN, D. Time-intensity reciprocity under various conditions of adaptation and backward masking. Journal of Experimental Psychology. 1966, 71 , 543-549.

KAHNEMAN, D \& NORMAN, J The time intensity relation in visual perception as a function of the observer's task. Journal of Experimental Psychology, 1964, 68, 215-220.

KEPPEL, G., \& MALLORY, W. A Presentation rate and instructions to guess in free recall. Journal of Experimental Psychology, 1969, 79, 269-275.

LICHTENSTEIN, M \& BOUCHER, $R$ Minimum detectable dark interval between trains of perceptually fused flashes. Journal of the Optical Society of America, 1960, $50,461-466$.

LISS, $P$. Does back ward masking by visual noise stop stimulus processing? Perception \& Psychophysics, 1968, 4. 328-330.

ROBINSON, D. N. Disinhibition with binocular and interocular presentations. Journal of the Optical Society of America, 1968, 58, 254-257.

SCHURMAN, D. L., ERIKSEN, C. W.. \& ROHRBAUGH, J. Masking phenomena and time intensity reciprocity of form. Journal of Experimental Psychology, $1968,78,310-317$.

SPERLING, G. Successive approximations to a model for short term memory. Acta Psychologica, 1967, 27, 285-292. 